\title{
Staat van de bestuurskunde
}

\section{Samenvattend én persoonlijk slotakkoord ${ }^{*}$}

\author{
Thomas Schillemans
}

Onder redactie van Philip Marcel Karré, Thomas Schillemans, Martijn van der Steen en Zeger van der Wal

Als geïnstitutionaliseerd vakgebied is de bestuurskunde in Nederland nu ongeveer veertig jaar oud. De Vereniging voor Bestuurskunde is opgericht in 1974; de eerste zelfstandige studierichting begon in Twente in 1976. $40+$ is een leeftijd die vaak aanzet tot fundamentele zelfreflectie en soms tot domme dingen. In deze serie buigen wij ons over kernvragen voor het vakgebied. Dient de bestuurskunde zich meer op de praktijk of juist op de pure wetenschap te richten? Is bestuurskunde eigenlijk een eigenstandige discipline of juist een onderdeel van de politicologie, de juridische of de managementwetenschappen? Wat zijn belangrijke ontwikkelingen in de afgelopen jaren en welke verwachtingen zijn er voor de toekomst? In 2015 en 2016 gingen wij hier in een serie artikelen nader op in. Dit is het laatste artikel uit deze serie. Wij hopen dat hierdoor een brede discussie van de grond zal komen over staat en toekomst van de bestuurskunde en nodigen onze lezers van harte uit daaraan mee te doen. U kunt reageren op de Facebook-pagina van de VB, facebook.com/bestuurskunde.nl.

De bestuurskunde heeft in Nederland een wat ambigue maar in elk geval eerbiedwaardige en volwassen leeftijd bereikt. Het is nu 41 jaar geleden dat de eerste bestuurskundige opleiding het licht zag (Braun et al., 2015). De Vereniging Bestuurskunde (VB) is nog eens twee jaar ouder. Het tijdschrift Bestuurswetenschappen kon al zijn zeventigste verjaardag vieren (Reussing, 2016). De eerste Nederlandse hoogleraar Van Poelje werd 89 jaar geleden benoemd. En het canonieke artikel van Wilson over The Study of Administration is inmiddels 130 jaar oud (Van Ostaijen, 2016). Tegen de achtergrond van deze disciplinaire coming of age is in de afgelopen anderhalf jaar een serie artikelen verschenen in dit tijd-

* Dr. T. Schillemans is universitair hoofddocent aan de Universiteit Utrecht. Ik dank graag Rixt Riemersma voor haar ondersteuning bij het tot stand komen van dit artikel. Het artikel is mede geïnspireerd op de discussie die we in de leerstoelgroep Public Governance \& Management van de Universiteit Utrecht (USBO) hebben gevoerd over de staat van onze discipline. Dank ook aan Mark Bovens, Joram Feitsma, Paul 't Hart, Philip Karré, Martijn van der Steen en Zeger van der Wal voor inspiratie en feedback op een eerdere versie van dit artikel. 
schrift over de staat en toekomst van de bestuurskunde (Gadellaa et al., 2015; Braun et al., 2015; Van der Steen, 2016; Karré, 2016; Van der Wal, 2016; Van Ostaijen, 2016). Vanuit verschillende invalshoeken hebben de auteurs daarin gereflecteerd op het vakgebied: op sterke kanten en kwetsbaarheden, op kansen en bedreigingen. In dit laatste artikel van de serie maak ik een samenvattende en persoonlijke balans op, waarbij het zwaartepunt in de loop van de tekst verschuift van samenvattend naar persoonlijk.

\section{Bestuurskunde als eerstelijnswetenschap}

Bestuurskunde is naar zijn aard een eerstelijns wetenschapsgebied. De bestuurskunde leunt traditioneel op de eufemistisch gemunte steundisciplines sociologie, politicologie, recht, economie en management. Bestuurskundige kennis is van daaruit altijd domein-gericht en betrokken op concrete bestuurlijke verschijnselen in hun specifieke context. De bestuurskundige verhoudt zich tot de andere sociale wetenschappen enigszins zoals de huisarts zich verhoudt tot medisch specialisten. De specialisten excelleren in specifieke kennis op één terrein, de huisarts moet van alle markten thuis zijn en vooral ook in staat zijn om in goede verbinding te staan met die verschillende specialisatiegebieden. De toegevoegde waarde schuilt in het integratieve karakter van het beroep en de inzet om de patiënt in zijn dagelijkse omgeving, inclusief allerlei niet-medische zaken die wel van belang zijn, concreet te helpen. Een ander beeld voor de bestuurskunde is dat van de vos die 'many little things' weet en zich daarmee onderscheidt van de egel, naar het klassieke onderscheid van Isaiah Berlin (Tetlock, 2005). Dit eerstelijns en integratief karakter is niet iets om geringschattend over te doen. Juist in dit vermogen om op pragmatische wijze inzichten en methoden te combineren en met elkaar in verband te brengen schuilt het vermogen om situaties goed in te schatten en betrouwbare voorspellingen te doen (Tetlock, 2005).

Het integratief vermogen is traditioneel van groot belang voor het vakgebied van de bestuurskunde (Van Ostaijen, 2016) en geldt doorgaans als unique selling point (Braun et al., 2015, p. 85). De bestuurskunde kan op haar beste dagen vorm geven aan complexe vraagstukken door inzichten uit verschillende disciplines samen te brengen (Van der Steen, 2016, p. 88).

De bestuurskunde staat steeds op het punt om een eigenstandige discipline te worden (Karré 2016), zonder dat punt echt te bereiken. Enerzijds is de Nederlandse bestuurskunde relatief sterk geïnstitutionaliseerd tot een eigenstandige discipline. Anderzijds is ook duidelijk dat de bestuurskunde in theoretisch, conceptueel en methodologisch opzicht nog steeds sterk op meer specialistische sociale en geesteswetenschappen leunt. Dit komt bijvoorbeeld mooi naar voren in het vergelijkende onderzoek onder bestuurskundige onderzoekers van Gadellaa et al. (2015). Zij laten aan de ene kant zien dat het aantal bestuurskundige onderzoekers dat zelf een bestuurskundige opleiding heeft genoten in Nederland meer dan twee keer hoger is dan in andere Europese landen, waar onderzoekers in veel sterkere mate een achtergrond in politicologie of managementwetenschappen heb- 
ben. Anderzijds laten zij ook zien dat nog steeds bijna de helft van de bestuurskundige onderzoekers zelf een niet-bestuurskundige achtergrond heeft.

Vanaf de jaren negentig heeft het domein van de bestuurskunde zich verbreed en is het aantal disciplines waar de bestuurskunde uit put sterk toegenomen. Het zijn weer Gadellaa et al. (2015) die laten zien dat de vijf klassieke steundisciplines weliswaar nog steeds belangrijk zijn, maar dat er ook veel andere disciplines bij zijn gekomen. Dat kan voor de aandachtige lezer van Bestuurskunde geen verrassing zijn. In de afgelopen jaren verschenen er themanummers waarin de raakvlakken tussen bestuurskunde en communicatiewetenschap (De Bruijn et al., 2012) en psychologie (Schillemans \& De Vries, 2016) werden verkend en zijn ook taalwetenschappers, geografen, data-analisten, filantropen en milieukundigen aan bod gekomen. In het onderzoek ontstaan zo steeds nieuwe niches waarin andersoortige vraagstukken met andersoortige combinaties van methoden worden onderzocht. Ook in het bestuurskundige opleidingsaanbod ontstaat steeds meer differentiatie tussen opleidingen in Nederland. Braun et al. (2015, p. 85) schrijven: 'Waar sommige opleidingen vooral institutionele vraagstukken centraal stelden, richtten andere zich meer op managementvraagstukken of de relatie tussen overheid, samenleving en marktpartijen.'

\section{Op de voorgrond: spanning tussen rigueur en relevantie}

Dé spanning in de ontwikkeling van de bestuurskunde, die in alle artikelen uit deze serie en ook in nagenoeg alle discussies die ik ooit over het onderwerp heb bijgewoond, naar voren komt, raakt direct aan het spanningsveld tussen wetenschappelijke pretentie en maatschappelijke relevantie. Als eerstelijns wetenschap wil de bestuurskunde praktisch en bestuurlijk relevant zijn; als eerstelijns wetenschap heeft het ook wetenschappelijke ambities. Dat levert spanningen op die in debatten (Braun et al., 2015), surveys (Gadellaa et al., 2015; Van der Steen, 2016), interviews (Karré, 2016) én meer persoonlijke essays (Van der Wal, 2016; Van Ostaijen, 2016) steevast naar de voorgrond treden.

Van der Steen (2016, p. 86) bijvoorbeeld signaleert expliciet de spanning tussen rigueur en relevantie. Om maatschappelijk relevant te zijn zal de bestuurskunde logischerwijs antwoord moeten geven op vragen uit de maatschappij en in het bestuur. Toch lijkt dit steeds moeilijker te zijn vanwege de steeds hogere eisen van wetenschappelijke rigueur. Technische perfectie van een onderzoeksdesign en het toepassen van een bepaalde methodologie noodzaken tot inperking van onderwerpen tot sub-compartimenten van deelproblemen. Scherper zicht op de delen gaat dan hand in hand met het uit het zicht verdwijnen van het grotere geheel. Bovens (2016) formuleert hetzelfde provocatief voor de disciplinaire neven en nichten van de politicologie waar hij stelt dat de politieke wetenschappen dankzij steeds betere onderzoeksmethoden steeds meer weten maar tegelijk steeds minder te vertellen hebben.

De andere auteurs in deze serie zitten overwegend op dezelfde lijn. Braun et al. (2015, p. 88) oordelen dat de bestuurskunde is 'veracademiseerd' en dat dit niet samengaat met publieke betrokkenheid. Gadellaa et al. (2015) vroegen Europese 
onderzoekers om na te denken over de staat van de bestuurskunde en algemene trends in het vakgebied. Hieruit bleek dat Nederlandse bestuurskundigen zich minder sterk op toegepast onderzoek en de praktijk richten dan in de rest van Europa gebruikelijk is. Het is volgens Braun et al. (2015, p. 90) de interne logica van de academische wereld die bestuurswetenschappers dwingt internationale publicaties met stip bovenaan hun prioriteitenlijstjes te zetten. Toch is het volgens Van der Steen (2016, p. 87) te gemakkelijk om financieringsmodellen en prestatie-indicatoren in de academische gemeenschap als excuus te gebruiken. Het gaat volgens hem ook om een mentaliteit bij de betrokkenen. De publicatiedruk bestaat zonder meer óók omdat bestuurskundigen zich ernaar gedragen. Tekenend is ook dat de nieuwe generatie hoogleraren deze spanning tussen rigueur en relevantie afdoet als een schijntegenstelling (Karré, 2016).

Volgens Van der Steen (2016, p. 88) moeten bestuurskundigen meer oog hebben voor de maatschappelijke relevantie van hun werk. Bestuurskundigen zouden volgens hem dicht op de praktijk moeten opereren maar er tegelijk ook kritisch op moeten blijven reflecteren, om zo voor scherpte te zorgen in beleidsprocessen en bestuurlijke actoren gevraagd en ongevraagd tegen te spreken. Karré (2016) komt tot een soortgelijke conclusie. Van der Wal (2016, p. 87) pleit in dat verband voor een goede samenwerking tussen overheidsprofessionals en hun toekomstige partners in andere sectoren door middel van netwerken. Ook heeft dit eenstemmige pleidooi voor relevantie consequenties voor het reguliere en postacademische onderwijs. Het volstaat niet om daarin te vertellen dat bestuurskundige praktijken grensoverschrijdend, collaboratief en integratief van aard zijn; de opleidingen moeten het de studenten ook leren doen en laten doen. Het is belangrijk om studenten op alle niveaus van de opleiding echt grensoverschrijdend te leren samenwerken met andere disciplines (Van der Wal, 2016).

Het is voor deze slotbeschouwing een belangrijke constatering dat de verschillende bijdragen aan deze serie steeds bij ditzelfde fundamentele spanningsveld uitkomen en dat de betrokkenen - hoewel soms zelf representatief voor de meer professioneel-academische mores met zijn onderzoeksbeurzen, moeilijke methoden en publicatieprikkels - allemaal de schaduwzijde van deze ontwikkeling benoemen. Toch blijven daarbij minstens twee punten relatief onbenoemd.

In de eerste plaats verdient de zonzijde van de academisering van de bestuurskunde ook een zonniger vermelding. De academiserende bestuurskunde is de afgelopen decennia sterk geïnternationaliseerd. De redacteuren van deze themaserie zijn nog overwegend opgeleid door Nederlandse bestuurskundigen, die veel in het Nederlands schreven aan de hand van vaak Nederlandse concepten over vooral Nederlandse bestuurlijke verschijnselen. Uiteraard was er toen ook al internationale uitwisseling, maar die heeft zich in de afgelopen jaren sterk verdiept. Dat heeft geleid tot een internationale uitwisseling en versterking van ideeën in krachtige internationale sub-gemeenschappen van onderzoekers en heeft ook geleid tot meer internationaal vergelijkende projecten. Dat is, met de nodige mitsen en maren ten aanzien van de kwaliteit van dat vergelijkende onderzoek (Verhoest et al., 2017), niettemin echt een belangrijk winstpunt. Ook is de meer rigoureuze peer review in de geacademiseerde bestuurskundepraktijk een belangrijk winstpunt (schrijf ik in het volle besef dat de praktijk van peer review 
veel te vaak achterblijft bij het ideaal). Maar toch, zelfs dan roept de anticipatie op de peer review al kritische zelfreflectie op die kwaliteitsimpulsen geeft (vgl. Schillemans, 2016). Tot slot zijn het methodologische onderwijs en de methodologische gereedschapskist van de bestuurskunde in de afgelopen jaren breder en sterker geworden. De huidige generatie promovendi is in wetenschaps-technisch opzicht zonder meer veel beter dan eerdere generaties. Daar is de schaduwzijde van bedreigde relevantie weliswaar mee verbonden, maar het tekent ook de zonzijde van sterkere rigueur, die het ook verdient om in het zonnetje te worden gezet. Bestuurskundige wetenschappers zijn in ieder geval in technische zin ook beter geworden. Inmiddels zijn we in de situatie beland dat het vakgebied niet alleen inhoudelijk maar ook methodologisch put uit tal van bronnen. Er zijn niet veel vakgebieden die in gelijke mate multi-methodisch zijn zoals de bestuurskunde dat nu is (vgl. Hood, 2011) en dat is als zodanig iets om te koesteren.

In de tweede plaats is opvallend in het rigueur-versus-relevantie-debat dat de praktijkgerichte bestuurskundige de neiging heeft om een waardevolle maar ook heel specifieke invulling te geven aan die rol, namelijk die van de 'bestuurskundig adviseur' (Braun et al., 2015). Het is een adviseur die de bestuurder begrijpt, die wijs is op grond van ervaring en veel weet van het bestuur. Het is een adviseur die bestuurders en professionals aanzet tot reflectie maar ook kritisch tegenspel biedt en een spiegel voorhoudt (Van der Steen, 2016). De bestuurskundig adviseur is in veel opzichten te vergelijken met een coach. Dat is belangrijk en waardevol, maar laat onverlet dat de praktijkgerichte bestuurskunde ook een andere rol kan spelen door als vraagbaak en kennispartner (deel)antwoorden te geven op de soms platte kennisvragen die leven in het bestuur. In zijn canonieke artikel over de bestuurskunde definieerde Wilson (1887; zie ook Van Ostaijen, 2016) de missie van het vakgebied als het bestuderen van wat de overheid kan doen en hoe het dat het beste kan doen. Nog steeds willen overheden vaak weten 'wat werkt' en hoe zij beleidsdoelstellingen kunnen bereiken (en, vooruit, legitimeren). Maar de bestuurskundige adviseurs zijn vaak terughoudend om die vraag te beantwoorden, waardoor anderen, zoals economen (Baarsma \& Janssen, 2007) en psychologen (De Ridder et al., 2016), dergelijke operationele - en in essentie bestuurskundige - vraagstukken overnemen. De buitenwereld vraagt vaak om kennis over hoe het moet of kan, de bestuurskunde is relatief sterker in de analyse van hoe het gaat en in het uitleggen dat en waarom het ingewikkeld is. Op dit punt zijn er voor de praktijkgerichte bestuurskunde, in samenwerking met andere disciplines, nog belangrijke stappen te zetten om de belofte van haar internationale (Van Ostaijen 2016) en nationale aartsvaders (Braun et al., 2015) in te lossen opdat het vakgebied echt bijdraagt aan de omgang met maatschappelijke vraagstukken door het bestuur. Het pleidooi van Van der Wal (2016) voor het opleiden van de 21ste-eeuwse publieke manager sluit hier ook goed bij aan.

\section{Op de achtergrond: waar zijn de kritische en publieke bestuurskunde?}

De academiseringsdiscussie speelt niet alleen in de bestuurskunde maar zeker ook, en in nog veel scherpere bewoordingen, in de politicologie (Bovens, 2016) en 
sociologie (Burawoy, 2005). Alleen al een snelle vergelijking met deze disciplines is op het eerste gezicht weldadig voor de bestuurskunde. Als beleidsrelevantie belangrijk is voor een sociale wetenschap, en als de sociologie en politicologie als ijkpunt worden genomen, dan zit het 'bij ons' wel snor met de verhouding tussen praktijkrelevantie en academisering. De bestuurskundige zorg dat de toenemende (en toe te juichen) rigueur de relevantie ondermijnt, verbleekt in contrast met de stand van zaken in die andere disciplines.

Maar de vergelijking laat op het tweede gezicht ook iets heel anders zien: de bestuurskunde is in vergelijking met sociologen en politicologen wel een héél braaf wetenschapsgebied dat, zowel in academische als in beleidsgerichte vorm, vaak weinig kritisch en reflexief is.

Burawoy onderscheidde de sociologie op twee dimensies. Aan de ene kant is er een onderscheid tussen wetenschappers naar het publiek dat zij adresseren. De kernvraag is dan of zij schrijven over problemen die door vakgenoten zijn geïdentificeerd in artikelen die vervolgens weer door vakgenoten worden gelezen, of dat zij schrijven voor een buiten-academisch publiek van bestuurders of burgers over de problemen die bij dat buiten-academische publiek leven. Het moge duidelijk zijn dat het onderscheid tussen rigoureuze en relevante bestuurskunde precies op dit breukvlak is gesitueerd. Aan de andere kant echter onderscheidt Burawoy óók de reflectieve, kritische wetenschap van instrumentele, positieve wetenschap. Exponenten van de kritische sociologie die voor een academisch publiek de impliciete vooronderstellingen van het vakgebied blootleggen en deconstrueren, zijn bijvoorbeeld Michel Foucaults (1989) analyse van disciplinering, toezicht en straf en Willem Schinkels (2008) recalcitrante sociologische hartenkreet 'Integreren? Nee bedankt!' Aan de andere kant is er ook een meer publieke sociologie, waartoe Burawoy (2005) zichzelf ook bekent, die zich juist actief op de niet-academische wereld richt. De Britse politicoloog Matthew Flinders is een goed voorbeeld van deze publieke benadering in zijn expliciete verdediging van de politiek (2012) tegen alledaags cynisme en met het oprichten van het Bernard Crick Centre for the Public Understanding of Politics.

Uiteraard zijn er ook in de bestuurskunde de nodige voorbeelden van reflectieve onderzoekers en zijn er ook bestuurskundigen die zich juist op het publieke debat richten om bestuurlijke elites een kritische spiegel voor te houden, zoals bijvoorbeeld en met name Paul Frissen (2016) doet. Desalniettemin is de omvang van de meer kritisch-reflectieve bestuurskunde, ook in vergelijking met sociologen en politicologen, gering. Het feit dat Foucaults governmentality in dat verband zeer vaak als voorbeeld naar voren komt, spreekt, naast het feit dat het een vorm van disciplinaire diefstal is, boekdelen.

Van Ostaijen (2016) stelt terecht dat het vakgebied van de bestuurskunde nooit helemaal is losgekomen van zijn ontstaansmoment, toen het als apolitieke en praktijkgerichte discipline is gedefinieerd. De 'founding fathers van de bestuurskunde (...) wilden de bestaande instituties niet omverwerpen maar ze professionaliseren' (Braun et al., 2015, p. 83). Het vakgebied is van meet af aan zo op de eerste dimensie van Burawoy gedefinieerd als een instrumenteel vakgebied. De meer kritisch-reflectieve rol is daarbij veel minder tot wasdom gekomen. Dat is als zodanig al een goede reden om de meer reflectieve dimensies van het vakge- 
bied meer te verkennen. Bovendien is er juist nu in het eerste kwart van de 21ste eeuw ook veel aanleiding om, in aanvulling op de rigoureuze en relevante bestuurskunde, ook te investeren in kritisch-reflectieve bestuurskunde.

Een eerste fundamenteel vraagstuk betreft de instrumentele aard van het vakgebied. Die instrumentaliteit is mogelijk geweest doordat de bestuurskunde zichzelf als vakgebied als het ware buiten het politieke gekrakeel plaatste. De bestuurskunde is geënt op het fundamentele onderscheid tussen politiek en beleid, waarbij de bestuurskunde buiten het eerste blijft en het tweede wil versterken (Van Ostaijen, 2016). In hedendaagse termen: het 'wat' van beleid is voor de politiek en de politicologen, het 'hoe' voor het bestuur en de bestuurskundigen. Door dit beginsel van apolitieke, technische en situationele expertise kunnen bestuurskundigen zich vervolgens in onderzoek en advies bezighouden met allerlei politiek en maatschappelijk brisante onderwerpen zonder politieke kleur te hoeven bekennen. Die neutraliteit was echter mogelijk en ook wel verdedigbaar onder specifieke condities van de tweede helft van de twintigste eeuw die inmiddels onder grote druk staan. Het politieke spectrum was om te beginnen stabiel en de grote politieke partijen waren bereid tot pragmatische samenwerking. Weliswaar was er een duidelijke onderlinge profilering en politisering in de tijden van verzuiling, op de achtergrond werkten de verschillende zuilen eendrachtig samen aan beleid dat recht deed aan de uitgangspunten van verschillende partijen (Andeweg \& Thomassen, 2011). De bestuurskunde kwam ook tot wasdom vanaf de jaren zeventig, in een context waarin de kennisinfrastructuur van het beleid werd uitgebouwd en de wetenschappelijke basis van beleid door velen belangrijk werd gevonden. En de bestuurskunde zag er geen been in om het gezag te dienen tegen de achtergrond van het democratische en rechtsstatelijke karakter van dat gezag.

In het eerste kwart van deze eeuw is er op deze punten veel in beweging. Politieke partijen zijn instabiel zoals kiezersvoorkeuren dat ook zijn. De consensusdemocratie waarin elites samenwerken, ontwikkelt zich tot een vetocratie waarin verantwoordelijken steeds sneller en vaker worden weggestemd (Naim, 2013). Steeds weer nieuwe partijen komen op of splitsen zich af en keren zich daarin tegen 'het' systeem en tegen 'de' elite. Ook de rol van kennis verandert in een klimaat dat in de VS eerst als fact-free en vervolgens post-truth politics is gedefinieerd. In die omstandigheden is het moeilijk om als discipline zonder veel nadere reflectie 'neutraal' te werken aan (kennis over) beter bestuur en beleid. Hetzelfde geldt ten aanzien van de internationalisering van kennis en onderzoek. Hoe staan bestuurskundigen ten aanzien van de verspreiding van hun inzichten in effectief beleid naar landen waar democratie en rechtsstaat ver te zoeken zijn? En hoe gaat de bestuurskunde om met het populisme waar grote en invloedrijke politieke partijen, zoals in de minder-Marokkanen-kwestie, de grenzen van de democratische rechtsstaat tarten? Is een apolitieke, technische en op beleidsverbetering gerichte bestuurskunde, een bestuurskundige die daarmee de facto de heersende bestuurlijke machten steunt, in die omstandigheden nog wel opportuun?

In het verlengde daarvan, maar zonder meer ook los daarvan, is het in tweede plaats goed als de bestuurskundig adviseur ook kritisch reflecteert op de eigen rol in relatie tot het bestuur. De bestuurskunde is in zekere zin de 'uncritical companion' van hedendaags bestuur, die vaak veel begrip toont en een luisterend oor 
heeft voor de complexe praktijk van publieke actoren. Deze coachende en kennisintegrerende rol kan zonder meer heel waardevol zijn. Tegelijk voeden wij als bestuurskundigen, ikzelf incluis, met onze begripvolle en meedenkende rol soms irreële verwachtingen van wat nieuwe bestuurlijke plannen kunnen opleveren. Daarmee dragen we mede bij aan de onvermijdelijke teleurstelling die op termijn ontstaat en, paradoxaal genoeg, ondanks de beste bedoelingen, aan teleurstellend bestuur. Neem bijvoorbeeld de verzelfstandiging van uitvoeringsorganisaties die aan het einde van de vorige eeuw, onder begeleiding van een koor van coachende en meedenkende bestuurskundigen, een hoge vlucht nam. Het was een beleidsprogramma met hoge verwachtingen, mede gevoed door de academische bestuurskunde, die op bijna alle punten niet zijn ingelost. Op EU-niveau is inmiddels eenzelfde discussie met hoge verwachtingen ten aanzien van zelfstandige agentschappen ontstaan, alsof het daar veel anders zou zijn dan op nationaal niveau. Of neem de roep om burgerparticipatie die vanaf de jaren zeventig klinkt en in steeds nieuwe verschijningsvormen hoopt meer draagvlak, bredere participatie en gemoderniseerde politieke verhoudingen te realiseren. Zijn we wel voldoende kritisch op het bestuur bij dit soort initiatieven en werken we wel hard genoeg om de inzichten in de effecten van participatie te aggregeren en effectief te communiceren aan het bestuur (zie Wille, 2011)? Want het is betreurenswaardig als bestuurlijke innovaties tot voorspelbare teleurstellingen leiden, zoals bijvoorbeeld de conclusie dat ook het G1000-initiatief er niet echt in slaagt om nieuwe groepen burgers te laten participeren in beleid (Boogaard \& Michels, 2016).

Tot slot is de vraag welke rol de bestuurskunde wil spelen in het maatschappelijk debat. Wie de media volgt, zelfs wie alleen de sociale media volgt, wordt dagelijks geconfronteerd met publieke uitspraken over wat de staat en wat het bestuur vermag. Ons object van kennis is permanent in het nieuws en staat voortdurend ter discussie. In het huidige klimaat bestaan er hoge verwachtingen van wat de politiek vermag, maar is er ook steeds heel veel kritiek op het bestuur zelf. Ook politieke partijen zijn steeds kritischer gaan spreken over de overheid, het interventievermogen van het bestuur alsook over ambtenaren (Schillemans \& Den Otter, 2014). Kritiek is goed en is op veel punten ook volkomen gerechtvaardigd. Maar het debat wordt wel vaak in erg platte tegenstellingen, in simplistische schemata voor of tegen de overheid, gevoerd. Ook treden wel erg vaak gemeenplaatsen en platitudes in de plaats van argumenten, zoals de claim dat de tijd van de maakbaarheid voorbij is of dat de traditionele werkwijzen van de overheid niet meer zouden passen bij de moderne omstandigheden (gaap!). Bestuurskundigen zijn vaak terughoudend om zich te engageren in dit debat, terwijl het wel over 'ons' kerndomein gaat, waar een schat van onderzoek over bestaat dat zich met steeds rigoureuzer onderzoeksmethoden ontwikkelt. Waar is de publieke bestuurskunde die zich roert in het debat over de kwaliteit van bestuur en beleid? 


\section{Tot besluit: een agenda}

De bestuurskunde is volwassen maar nog lang niet af of volgroeid. Dit artikel heeft de hoofdlijnen willen samenbrengen uit het debat over de staat van de bestuurskunde die in de afgelopen periode in Bestuurskunde en op andere plaatsen is gevoerd. Met dit eindpunt van de serie is het debat natuurlijk nog lang niet beëindigd, en gelukkig maar. Voor de komende jaren zijn in ieder geval onderstaande agendapunten van groot belang.

Academische bestuurskunde: instrumentele kennis voor een academisch publiek

1 Versterken maatschappelijke relevantie van onderzoek (dat in technisch opzicht gelukkig steeds beter wordt)

2 Koesteren van het bijna unieke multi-methodische en kennis-integratieve karakter van het vakgebied

Praktijkgerichte bestuurskunde: instrumentele kennis voor een algemeen publiek

1 Versterken van de rol van kennisproducent voor het bestuur

2 Aan studenten leren hoe ze in praktijken echt effectief over grenzen kunnen werken

Kritische bestuurskunde: kritische kennis voor een academisch publiek

3 Organiseren zelfkritiek op blinde vlekken en impliciete (politieke) aannames in het vakgebied

4 Stimuleren kritische reflectie op de relatie van het bestuurskundige vakgebied tot bestuurders in de onrustige machtsconstellaties van de 21ste eeuw

Publieke bestuurskunde: kritische kennis voor een algemeen publiek

5 Versterken van het maatschappelijk debat over de (on)zin van bestuur en beleid met feitelijke informatie uit onderzoek.

6 Initiatief nemen in de maatschappelijke discussie over de (on)zin van bestuur en beleid.

\section{Literatuur}

Andeweg, R., \& Thomassen, J. (2011). Van afspiegelen naar afrekenen? De toekomst van de Nederlandse democratie. Leiden: Leiden University Press.

Baarsma, B., \& Janssen, K. (2007). Selectie sturingsinstrumenten: Op weg naar een roadmap. Amsterdam: SEO Economisch Onderzoek.

Boogaard, G., \& Michels, A. (2016). G1000: Ervaringen met burgertoppen. Den Haag: Boom Bestuurskunde. 
Bovens, M. (2016). Een pleidooi voor meer publieke politicologie. Res Publica, 58(1), 102-107.

Braun, C., Fenger, M., Hart, P. 't, Veer, J. van der, \& Verheij, T. (2015). Quo vadis, Nederlandse Bestuurskunde? Bestuurskunde, 24(4), 82-92.

Bruijn, H. de, Schillemans, T., \& Steen, M. van der. (2012). Framing framing: Betekenisgeving en besluitvorming over beleid. Bestuurskunde, 21(4), 2-8.

Burawoy, M. (2005). For public sociology. American Sociological Review, 70(1), 4-28.

Flinders, M. (2012). Defending politics: Why democracy matters in the 21st century. Oxford: Oxford University Press.

Foucault, M. (1989). Discipline, toezicht en straf: De geboorte van de gevangenis. Groningen: Historische Uitgeverij Groningen.

Frissen, P. (2016). Het geheim van de laatste staat: Kritiek van de transparantie. Amsterdam: Boom.

Gadellaa, S., Curry, D., \& Walle, S. van de. (2015). Hoe bestuurskundig is de bestuurskunde? Bestuurskunde, 24(3), 67-79.

Hood, C. (2011). Public management research on the road from consilience to experimentation? Public Management Review, 13(2), 321-326.

Karré, P.M. (2016). Bouwen aan de ideale bestuurskunde. Bestuurskunde, 25(2), 79-89.

Naim, M. (2013). The end of power: From boardrooms to battlefield and churches to states, why being in charge isn't what it used to be. New York: Basic Books.

Ostaijen, M. van. (2016). De wil van Wilson. Bestuurskunde, 25(4), 94-104.

Reussing, R. (2016). Bestuurswetenschappen 70 jaar: de mannen (en een vrouw) van het eerste uur. Bestuurswetenschappen, 70(4), 5-17.

Ridder, D. de, Kroeze, F., \& Vet, E. de. (2016). Nudging: next questions. Bestuurskunde, 25(3), 46-52.

Schillemans, T. (2016). Calibrating public sector accountability: Translating experimental findings to public sector accountability. Public Management Review,18(9), 1400-1420.

Schillemans, T., \& Otter, P. den. (2014). Groeiend ongemak: Bestuurderspartijen en de constructie van het vertrouwen in de overheid. Bestuurskunde, 23(2), 61-70.

Schillemans, T., \& Vries, G. de. (2016). De Homo Psychologicus op het Schip van Staat: Gedragskennis in bestuur en beleid. Bestuurskunde, 25(3), 3-8.

Schinkel, W. (2008). De gedroomde samenleving. Zoetermeer: Uitgeverij Klement.

Steen, M. van der. (2016). Wat hebben wij aan u? Bestuurskunde, 25(1), 78-89.

Tetlock, P.E. (2005). Expert political judgment: How good is it? How can we know? Princeton University Press.

Verhoest, K., Vandenabeele, W., Wynen, J., \& Walle, S. Van de. (2017). Challenges for large-scale international comparative survey-based research in public administration. In E. Ongaro \& S. van Thiel (Eds.), The Palgrave handbook of public administration and management in Europe (te verschijnen). London: Palgrave.

Wal, Z. van der. (2016). De 21ste-eeuwse overheidsmanager. Bestuurskunde, 25(3), 78-89.

Wille, A. (2011), Democratische drempels: De moeizame relatie tussen participatie en democratie. In R. Andeweg \& J. Thomassen (red.), Democratie doorgelicht: Het functioneren van de Nederlandse democratie (pp. 103-118). Leiden: Leiden University Press.

Wilson, W. (1887/1941). The study of administration. Political Science Quarterly, 2(2), 197-222. 